\title{
Dynamic Interaction of Renewable Hybrid Power Plant with Grid
}

\author{
R. Das ${ }^{1}$, P. Bajpai ${ }^{2}$ and A. K. Sinha ${ }^{2}$ \\ ${ }^{1}$ Department of Electrical and Electronics Engineering \\ Don Bosco College of Engineering and Technology \\ Azara, Guwahati - Assam, 781017 (India) \\ Phone/Fax number: +91-03612841949, e-mail: dasrandas@gmail.com \\ ${ }^{2}$ Department of Electrical Engineering \\ Indian Institute of Technology Kharagpur \\ Paschim Midnapore-721302, West Bengal, India
}

Phone: +91-03222-282261, fax: +91-03222-282262, e-mail: pbaipai@ ee.iitkgp.ernet.in, aksinha@ ee.iitkgp.ernet.in,

\begin{abstract}
Distributed generation can appear in different forms ranging from conventional technologies (internal combustion engine, photo-voltaic cell etc.) to advanced ones (micro turbine, fuel cell etc.). Among them, wind generation is widely utilized with a hybrid energy storage technology. In hybrid systems fuel cell generator may be used as a supplement because wind generator output fluctuates with weather conditions. Fuel cells are very attractive to be used with intermittent sources of energy, because of high efficiency, fast load response, modularity and fuel flexibility. Simulation studies have proved the feasibility of coordinating fuel cell with wind generator to supply constant or dynamic load for either gridconnected or stand alone applications. In this paper, a dynamic model of grid integrated wind generator-fuel cell hybrid system connected to the test system of distribution network is developed. Dynamic behavior of voltage, power, torque, frequency etc. have been studied at the time of starting of wind generator and faults in the network. The developed model, being simple, could provide a useful tool for the planning of distributed generation.
\end{abstract}

\section{Key words}

Dynamic model, Fuel cell, Hybrid system, Wind generator.

\section{Introduction}

Need for installation of modular, renewable or nonrenewable generation plants near load centers has come up to reduce the transmission losses and avoid power congestion. These small-scale generators when embedded in the distribution network are called embedded generation or Distributed Generation (DG). Wind Generation has emerged as most promising among these generation technologies. Wind exists everywhere on the earth, and in some places with considerable energy density. Emerging awareness of the finiteness of the fossil fuel reserve and the adverse effects of burning those fuels for energy has caused to look for alternatives. This awareness is hastening the deployment of eco-friendly wind generator systems. Wind Generator (WG) may experience large variation in its output power under variable weather conditions. One method to overcome the above problem is to integrate WG with other reliable power sources.

Hybrid generation of WG-FC is studied in [1] in the noninterconnected grid. A part of the energy produced by the WG is expensed to produce hydrogen required by the FC. When wind power is less or not available, FC can supply the power needed by the network. This type of hybrid system works satisfactorily under variable nature of wind. FC can be installed with WG to contribute the primary frequency control [2]. A new control system for WG-FC hybrid system has been proposed in [3]. This control is needed to make the system operate correctly under different operating conditions. However, the study is made on a small network having only one bus, dynamic behavior of the system due to disturbances in the distribution network are not studied.

A simulation methodology for a wind energy conversion system incorporating fuel cell as a back up generator is proposed in [4]. Each component of the WG-FC hybrid system is modeled but the paper focuses only on the steady state analysis of the system. Transient responses of the WG-FC hybrid system for a step change in the electrical load and wind speed are presented in [5]. Hybrid photovoltaic-wind-diesel generation system is introduced for supplying a remote power load in [6].

A dynamic model of FC is developed and integrated with a distribution network in [7]. Variation of FC voltage with the load has been studied, however network side studies, like changes in real and reactive power flow in the network, are not discussed. In [8], squirrel cage induction machine used in WG has been compared with the others types of induction machine. This comparison shows that though squirrel cage machine limits the energy output of 
wind turbine, it is simple and reliable. Dynamic behavior of an Induction Generator (IG) which acts as co-generator with bulk Hydro-Quebec system is studied in [9], where IG is integrated into a distribution network connected to the grid. But the turbine side dynamics and its effect on system performance are not discussed.

This paper is organized in seven sections, where a dynamic model of WG-FC hybrid system has been developed for simulation studies of DG based power system. Dynamic behavior of grid connected DG enbedded distribution network has been studied at the time of starting of WG and faults at various buses in the network. Simulation case results are discussed and major conclusions are highlighted.

\section{Wind Generator System}

Wind turbine extracts the mechanical power from the wind. This extraction is a complex aerodynamic phenomenon. A simplified relation is used between mechanical power and wind speed to avoid this complexity when the electrical behavior of the system is the main point of interest $[10,11]$. The mechanical power output $\left(P_{m}\right)$ that a turbine produces is given by:

$$
P_{m}=\frac{1}{2} \rho A V_{w}^{3} \eta_{m} C_{P}(\beta, \lambda)
$$

Where $\rho$ is air density, $A$ is rotor cross sectional area, $V_{w}$ is wind speed, $\eta_{m}$ is efficiency of mechanical transmission and Power coefficient $\left(C_{P}\right)$ is a function of pitch angle $(\beta)$ and tip speed ratio $(\lambda)$.

IG size can vary from a few kilowatts to several megawatts [8]. Squirrel cage type IG is used as a WG in the simulation model used in this paper. In this type of generator $\mathrm{dc}$ excitation is not needed and maintenance cost is low. These machines are simple and reliable.

Three-phase stator and short circuited rotor windings of a squirrel cage IG can be represented by two sets of orthogonal fictitious coils. A generalized fifth order machine model has been developed in [12] by assuming q-axis 90 degree ahead of the $d$ axis. Two-phase fictitious coils are placed in direct (d) and quadrature (q) axes. The q-axis component of the stator voltaje is the real part of the bus bar voltaje and d-axis component is the imaginary part.

\section{Fuel Cell System}

FC is an electrochemical device used as reliable energy storage in combination with other renewable sources for stand-alone as well as grid connected systems. In this study, Solid Oxide Fuel Cell (SOFC) is chosen for the simulation. This type of FC has high operating temperature $\left(600-1000^{\circ} \mathrm{C}\right)$ and has high efficiency $(65 \%)$ compared to other types of FC. Due to very hightemperature exhaust gas can be used for combined heat and power application in residential or commercial buildings. SOFCs allow internal reforming of gaseous fuel inside the cell. This gives the cell multifuel capability [13]. The power density of SOFC is also very high (0.25$\left.0.3 \mathrm{~W} / \mathrm{cm}^{2}\right)$. The solid electrolyte yttria stabilized zirconia dioxide is ion-conducting at high temperature transferring the charges by $\mathrm{O}^{2-}$ ions [14]. Increased interest in using SOFC as an important DG has lead to use a gridconnected SOFC power plant model in the present work.

A FC plant can be represented as dc voltage source connected to the grid through an inverter and transformer is shown in Fig. 1. Terminal voltage of FC plant is $V_{F C}$, current is $I_{F C}$, internal voltage is $\mathrm{E}$ and ohmic resistance is $R_{F C} \cdot X_{s f}$ is line reactance and $V_{s} \angle 0^{\circ}$ is grid voltage. Output voltage of the transformer is $V_{f c} \angle \phi_{F C}$.

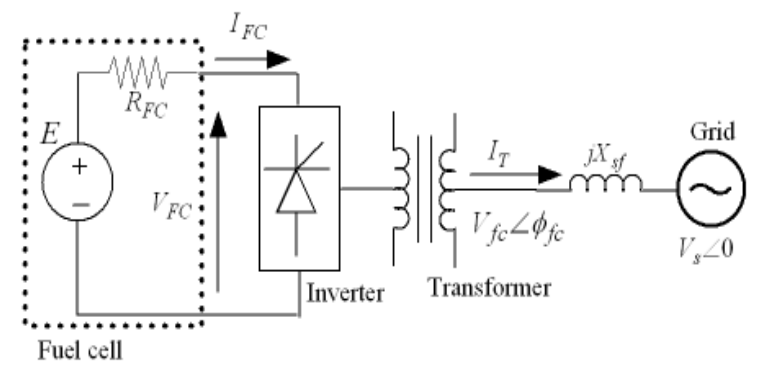

Fig. 1. Grid-connected fuel cell plant

To simplify the analysis, the following assumptions are made in the dynamic model for the FC stack:

- The stack is fed with hydrogen and oxygen,

- The gases are ideal,

- Temperature dynamics are ignored,

- The cannel that transport gases along the electrodes have a fixed volume.

\section{Hybrid System Model}

Details of modeling of WG and FC systems are not presented here due to space limitations. A hybrid model of FC and WG working as DG and integrated to a $25 \mathrm{kV}$ distribution network has been used for simulation case studies in this work. DGs are supplying a portion of network load while the remaining power is provided by a substation (Bus 250) as shown in the Fig. 1. $25 \mathrm{kV}$ test system used for simulation case studies have 13 buses and 11 lines distribution network [10]. The distribution network is modified by connecting a WG is connected to the bus 2513 through a transformer, therefore bus 51 is created between DG and transformer of 7.5 MVA. Bus 250 is connected to grid through a transformer. FCs are connected to the bus 255 through a $3 \mathrm{MVA}$ transformer.

Peak demand of the network is $9 \mathrm{MW}$. This load is supplied by the WG-FC hybrid generation. It is assumed that 2.25 MW load is uninterrupted load such as hospital and cold storage. Therefore, FC supplies this load being a reliable power source. FC operating cost is high, so it is not used to supply more than $2.25 \mathrm{MW}$. Rest of the generation to meet the peak demand is supplied from the WG units and grid power.

Each FC stack consists of 384 unit cells [7]. Each stack voltaje is 250 Volts. Inverter output voltage is $0.5 \mathrm{kV}$. Sine pulse width modulation is used in the inverter. To keep the DC bus voltage at $1.25 \mathrm{kV}$, five stacks are cascaded in series that generate total $0.375 \mathrm{MW}$ power. Six such set-ups are connected to the network so that total generation of FC is $2.25 \mathrm{MW}$. WG rating is $1.35 \mathrm{MW}$ and five such WGs are connected to the network that makes total 6.75 MW generation. Wind speed is taken as $9.5 \mathrm{~m} / \mathrm{s}$. 


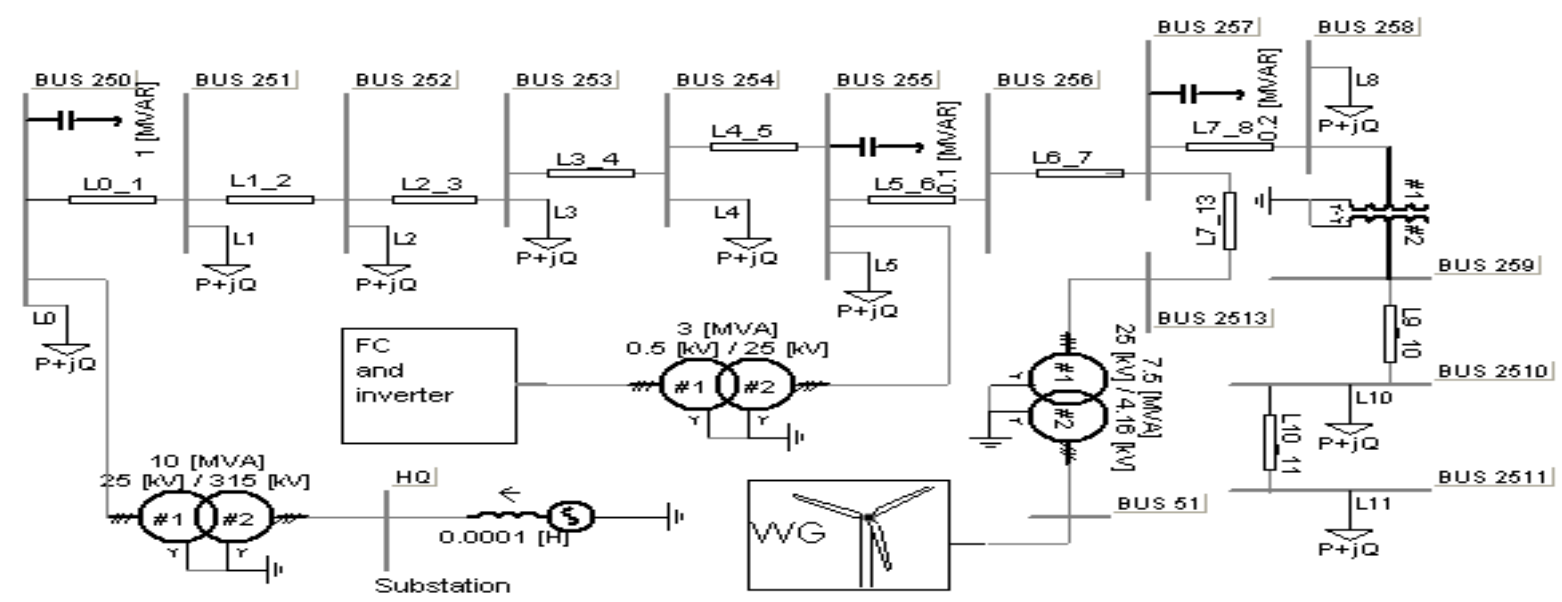

Fig. 2. The modified distribution network

\section{Study Objectives}

Voltage magnitude and angle at each bus of a power system are dictated by power flows from buses with excess of generation over demand to buses having generation deficit. At each bus, there is a balance between the power generated, the power consumed and the power transmitted to and from other buses. This balance also applies to the generating units since the mechanical power provided by the prime mover is equal to electrical power produced by the generator. In mechanical terms, this implies that the accelerating torque applied to the shaft by the prime mover is equal to the decelerating torque caused by the production of electrical power in the generator. Since the net torque is zero, the shaft rotates at constant speed. A major disturbance can perturb the above balance conditions. This induces large oscillations of power, voltage, and frequency and triggers a sequence of events [15].

The study objective of this paper is the development and analysis of a dynamic simulation model of WG-FC hybrid system embedded in a distribution network using the PSCAD/EMTDC software. FC is integrated in the network through an inverter to control the flow of real and reactive power as per the requirement of the network. Squirrel cage IG is coupled with the wind turbine. One of the major disturbances in the network is occurrence of fault. Dynamic behavior of the network and generators has been studied in case of 3-phase fault. Several case studies related to the fault at different buses in the network have been simulated along with one case study on starting effect of WGs. These dynamic behaviors are needed to design the current rating, voltage rating of protection equipment or any other equipment that is connected to the network. Further the dynamic model developed here can be used for simulation of DG based hybrid power system.

The focus for this work is to analyze the following studies

- The oscillation of power flow, voltage and frequency

- FC Voltage and currents at the time of starting of WG

- Fault disturbance in the distribution network in the presence of hybrid DG

\section{Simulation Results and Discussions}

\section{A. Case I}

In this case, dynamic behavior of the network is investigated when WG is started and connected to the network. Before the starting of WG, network load is supplied by FCs and grid. WG is connected to the network at 0.5 second. Owing to this connection, the flux is developed in the windings of the machine gradually. This flux interacts with the current and creates electrical torque. This electrical torque can be expressed in $\mathrm{d}-\mathrm{q}$ axis stator currents and fluxes.

Initially this electrical torque and mechanical torque act in the same direction. So, machine speed increases. When machine speed is greater than the synchronous speed, then $i_{d s}$ does not change its sign but $i_{q s}$ becomes negative. Where $i_{d s}$ and $i_{q s}$ are $\mathrm{d}$-axis and q-axis stator current respectively. Due to this electrical torque becomes positive and it starts acting opposite to the applied mechanical torque. The machine gradually settles its speed at steady state value just above the synchronous speed. Variation of electrical and mechanical torque with time is shown in Fig.3(a). Variation of speed of WG with time is shown in Fig.3(b). Fig. 3(c) shows the variation of $\mathrm{d}-\mathrm{q}$ axis fluxes of stator. Variation of $\mathrm{d}-\mathrm{q}$ axis currents of WG is shown in Fig. 3(d).

It is shown in Fig. 4(a) that a large amount of real power (3.5 MW) is needed by the WG at starting period. This power flows from the grid (bus 250) to the bus 2513 where WGs are connected, therefore bus voltages will no longer remain constant in this period and decreases sharply. At 1.35 second WGs start to supply power to the network and voltage reaches from $20 \mathrm{kV}$ to $26 \mathrm{kV}$ in 0.5 second. Variation of voltage (in pu) at bus 255 with time is shown in Fig. 4(b).

Variation of power loss in the line L 4-5 with time is shown in Fig. 4(c). It increases from 0.085 MW to 0.18 MW during the starting period of WG. Since power flow from grid to bus 2513 increases when WGs are starting, current flow in the line 4-5 increases from $0.2 \mathrm{kA}$ to 0.3 kA.Variation of current in line L4-5 is shown in Fig.4(d). 
During normal operation of WG (after 1.8 second), line losses settles at $0.04 \mathrm{MW}$ and current settles at $0.12 \mathrm{kA}$. As shown in Fig. 4(b), voltage of bus 255 drops from 1.08 pu to $0.8 \mathrm{pu}$, when all five WGs started together. This drop can be reduced by starting the WGs sequentially. This is illustrated in Fig. 5 by variation of voltage at bus 255 when only one WG started and voltage goes down to 0.98 pu only.
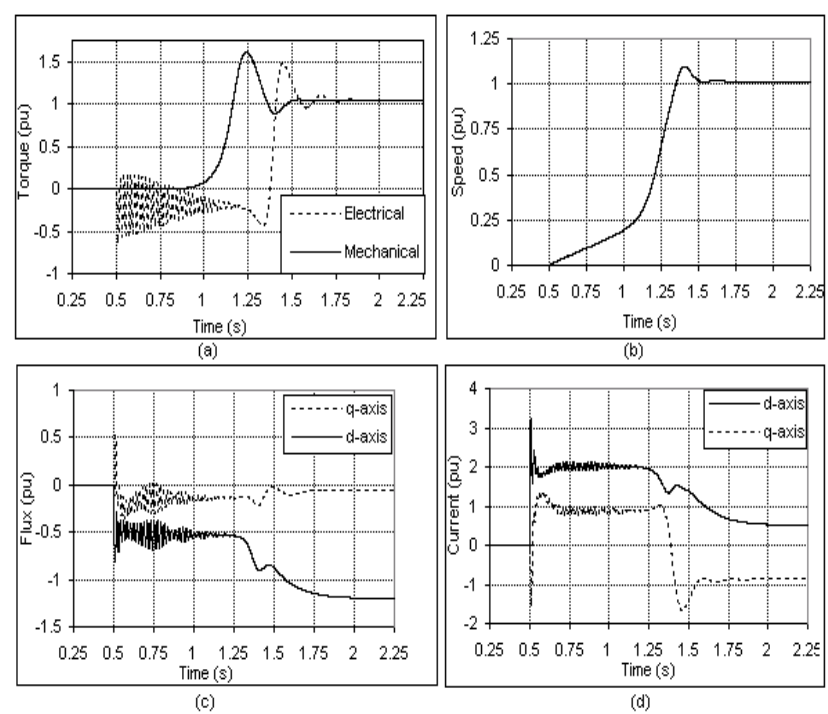

Fig. 3. Oscillation of electrical and mechanical torque (a), WG speed (b), WG d-q axis flux (c), WG d-q axis current (d) when WG is starting
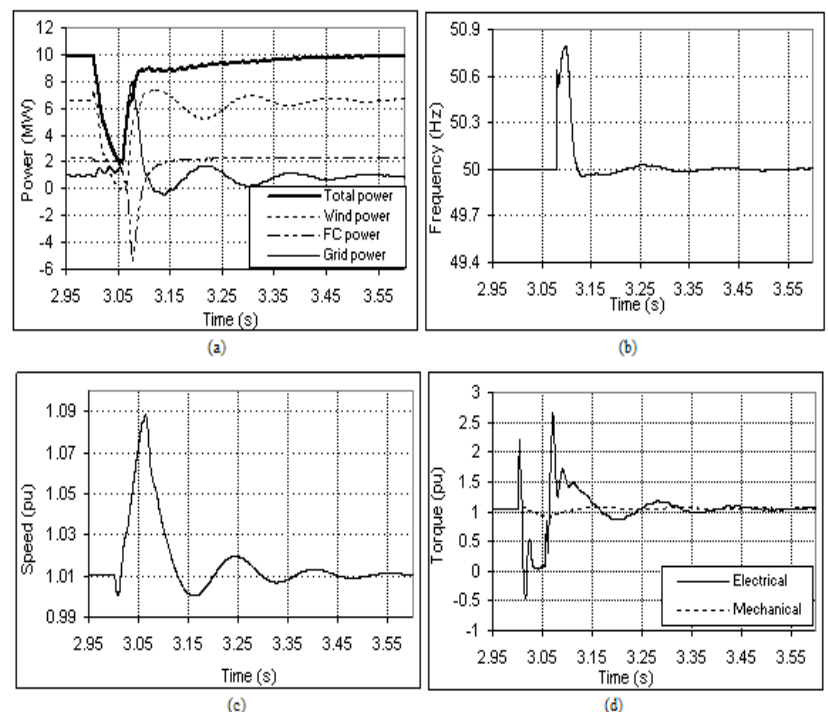

Fig. 4. Oscillation of power (a), voltage at bus 255 (b), line loss of line 4-5 (c), current of line L 4-5 (d) when all the WGs are simultaneously started

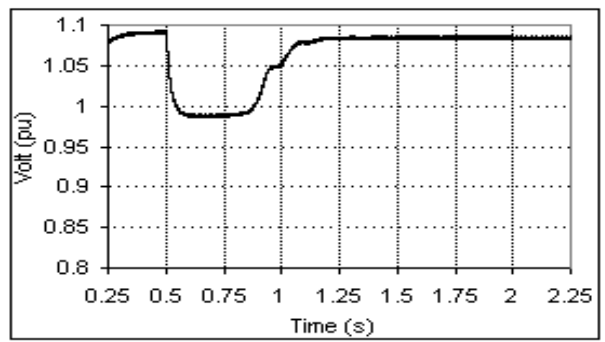

Fig. 5. Oscillation of voltage at bus 255, when only one WG unit started

\section{B. Case II}

Simulations of 3-phase fault at bus 250, 255 and 2513 have been studied in this case. These three buses are chosen because grid and generators are connected to these locations. Faults at these locations have severe effect on the generators connected to these buses compared to the faults of any other locations. In the simulation study, fault occurs at 3 second and is cleared in 0.05 seconds and the system is restored to normal condition before a transient fault by line closure.

1) Fault at bus 250

In this case study, 3-phase fault with fault resistance of $0.01 \mathrm{ohm}$ is introduced and cleared after 0.05 seconds at bus 250 where grid is connected through a transformer. After the occurrence of fault, voltage at the bus 250 drops to $2.5 \mathrm{kV}$. Variation of voltage at bus 250 with time is shown in Fig. 6(a).

Due to decrease in voltage of bus 250 , current flow increases in the neighboring lines. This increases the line losses considerably. Loss in line L4-5 is $0.6 \mathrm{MW}$ because of its high resistance $(0.72816 \mathrm{ohm})$. After the clearance of fault, line currents decrease. So, line losses also decrease. Variation of loss with time in the line L4-5 is shown in Fig. 6(b). Sudden decrease in voltages of all the buses causes a drop in load demand being voltage dependent. Total demand in the network starts to decrease immediately after the fault. Variations of total demand and generation with time are shown in the Fig. 7(a).

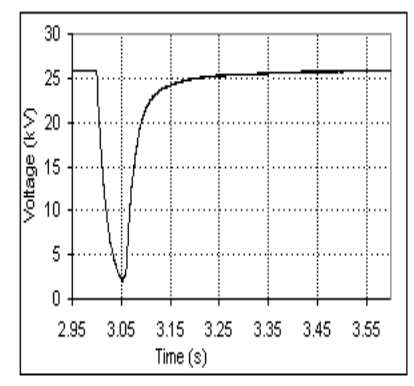

(a)

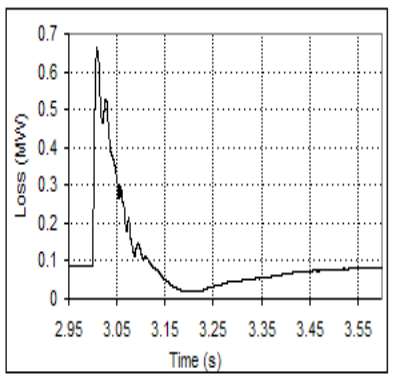

(b)
Fig. 6. Oscillation of voltage at bus 250 (a) and losses in line L4-5 (b) due to the fault at bus 250

During the fault period, the grid power increases gradually with a very small magnitude, therefore the frequency at bus 250 remains constant. However, after the clearance of fault grid power increases very sharply at 3.05 second (from 3.5 MW to 6.5 MW) and power supply at bus 250 also increases suddenly causing the frequency at bus 250 to increase as shown in Fig. 7(b). After few milliseconds frequency increase stops and starts decreasing with the increase in load demand as voltage restores to its normal value. Finally, frequency settles at $50 \mathrm{~Hz}$ as shown in the Fig. 7(b).

During the fault duration (0.05 seconds), speed of WG initially decreases slightly and then increases very sharply as shown in Fig. 7(c). Initially the load increases i.e. electrical torque applied to the WG increases and reaches to $2 \mathrm{pu}$, however wind speed is constant, therefore turbine output power remains constant as well as mechanical torque remains same but speed decreases. Following the drop in voltage, load also decreases. This 
causes decreases in electrical torque and therefore speed increases. Variation of electrical and mechanical torque with time is shown in Fig. 7(d).

At 3.05 second, fault is cleared and bus voltages are restored gradually due to characteristics of voltage dependent loads. At 3.35 second voltage restores fully as shown in Fig. 6(a) and load connected to the buses increases, therefore terminal voltage of WG also increases. Electrical torque of the WG gradually increases and after few oscillations it becomes equal to mechanical torque of the WG as shown in Fig. 7(d). Similarly, after the clearance of fault, speed of WG decreases and output power of the WG increases and settles at their respective pre-fault values.

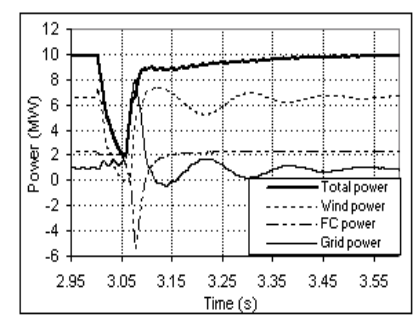

Time (s)

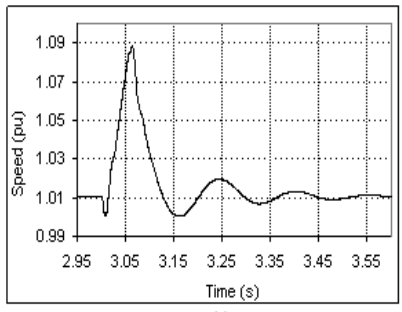

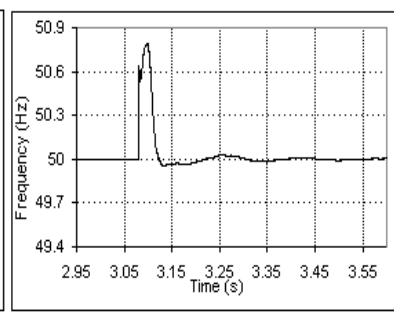

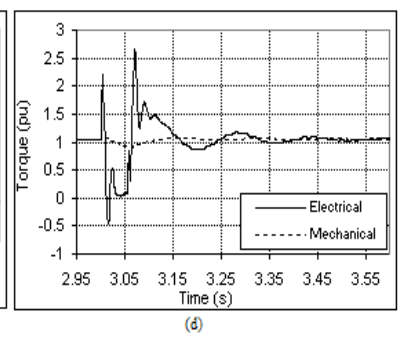

Fig. 7. Oscillations of power (a), frequency at bus 250 (b), speed of the WG (c), electrical and mechanical torque of WG (d) due to the fault at bus 250

\section{2) Fault at bus 255}

This section presents simulation study of 3-phase fault at bus 255 where FCs are connected. A 3-phase fault with fault resistance of $0.01 \mathrm{ohm}$ occurs at 3 second and cleared after 0.05 seconds. After the occurrence of fault, voltage at the bus 255 drops to $2.5 \mathrm{kV}$. Variation of voltage at bus 255 with time is shown in Fig. 8(a). A large current $(1.8 \mathrm{kA})$ flows from grid to bus 255 due to the fault at bus 255 . This increases the line losses considerably (14 MW) for the fault period. Loss in line L4-5 is $8 \mathrm{MW}$, because its resistance is more $(0.72816 \mathrm{ohm})$. Variation in loss with time in the L4-5 is shown in Fig. 8(b).

Since line losses increase, power demand in the network instantaneously increases very high $(25 \mathrm{MW})$ as shown in Fig. 8(c). WG output is limited to its rated value, therefore FC supplies the power through an inverter. Inverter switches sense the high current due to fault and FC stops the power supply immediately after the creation of fault. That causes the extra power demand required in the network to be supplied by the grid. After reaching a peak value, demand starts to decrease because all bus voltages decreases, therefore voltage dependent loads also decrease. Frequency of the network falls immediately after the occurrence of fault because power demand increases.
Oscillation of frequency at bus 250 with time is shown in the Fig. 8(d), where the frequency is less than $50 \mathrm{~Hz}$ for some period till 3.07 second, because of deficit in generation compared to total demand. When load demand decreases frequency increases. At 3.05 second, fault is cleared. Therefore, bus voltages are restored gradually. Output of the WG increases and settles at its pre-fault value.

\section{3) Fault at bus 2513}

WG units are connected to bus 2513 through bus 51 and a transformer. Simulation study of 3-phase fault at bus 2513 has been studied, where a fault with fault resistance of $0.01 \mathrm{ohm}$ occurs and cleared after 0.050 seconds. After the occurrence of fault, voltage at the bus 2513 drops to $2.5 \mathrm{kV}$. Variation of voltage at bus 2513 with time is shown in Fig. 9(a). Due to fault at bus 2513, large current flows from grid to bus 2513 that increases the line losses considerably. Loss in line L 4-5 is very high, because its resistance is more $(0.72816 \mathrm{ohm})$ and goes up to $3 \mathrm{MW}$ as shown in Fig. 9(b).
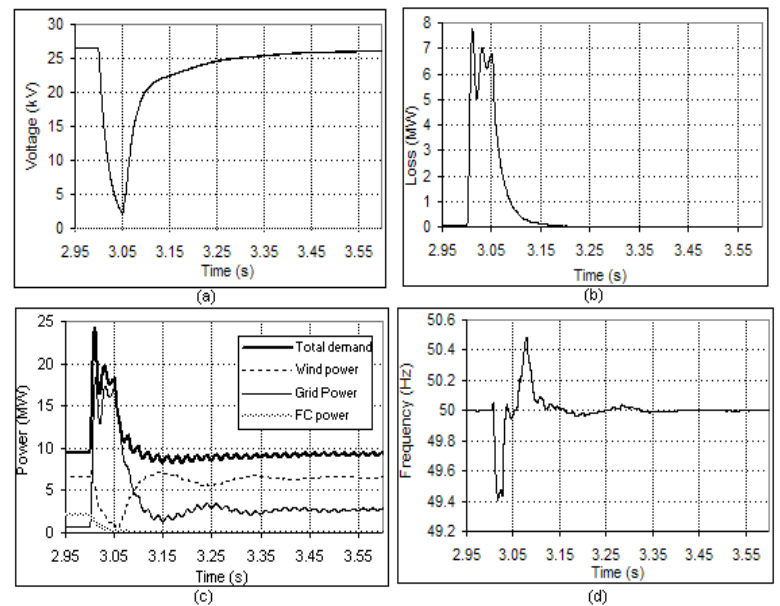

Fig. 8. Oscillation of voltage at bus 255 (a), line losses in L4-5 (b), power (c), frequency at bus 250 (d) due to the fault at bus 255
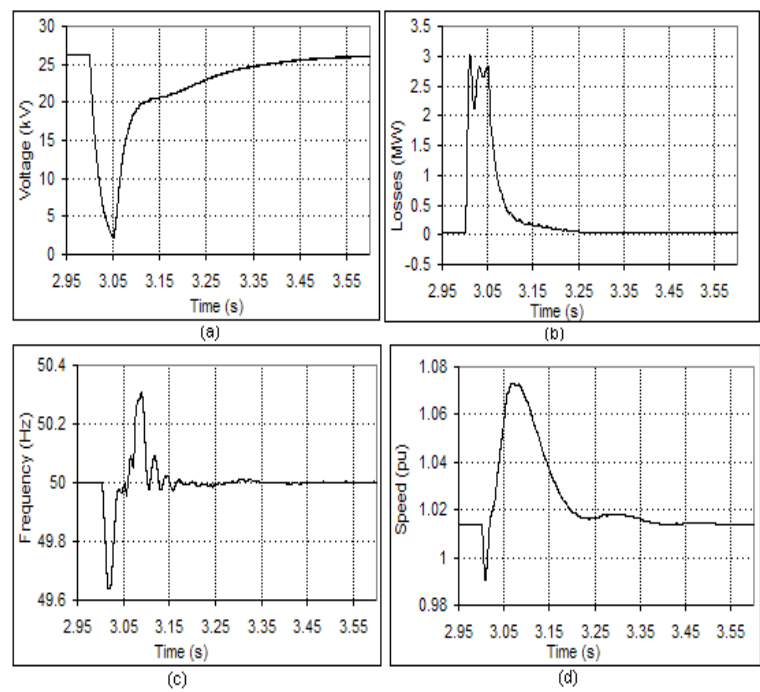

Fig. 9. Oscillation of voltage at bus 250 (a), line losses in L45 (b), frequency at the bus 250 (c), WG speed (d) due to the fault at bus 2513 
Oscillation of frequency of bus 250 is shown in the Fig. 9(c) where, frequency of the network falls immediately after the creation of fault at 3 second because power demand increases and after clearance of fault at 3.05 second, load demand decreases and frequency increases. Frequency increases till 3.07 second till then load demand is lower than the generation.

During the fault period, speed of WG first decreases then increases. It is shown in Fig. 9(d) that initially the power requirement increase i.e. electrical torque applied to the WG increases, therefore speed decreases, but when voltage starts to decrease then power requirement also decreases. Therefore, speed of WG increases due to decrease in electrical torque.

Since line losses increase, power demand in the network increases to $18 \mathrm{MW}$ instantaneously as shown in Fig. 10. WG output cannot be more than its rated value. FC supplies the constant power through a controlled inverter. Therefore, the extra load demand in the network is mostly supplied by the grid. After clearance of fault, demand decreases because all bus voltages decrease.

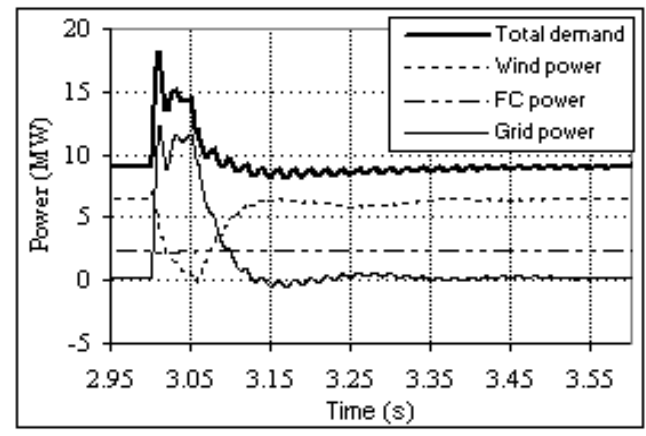

Fig. 10. Oscillation of power due to the fault at bus 2513

\section{Conclusion}

In this work, a dynamic model of WG-FC hybrid system which can be used as a model of reliable power source in DG based power system simulation has been developed. This paper has investigated dynamic behavior of DG embedded distribution network, which is connected to bulk generation system. Dynamic response of power flow, voltage, current and frequency due to the disturbance in the network have been investigated. The simulation results can be used to assess the dynamic behavior of the distribution network in the presence of DGs. Key findings of the simulation case studies are as follows:

- During the starting period of WG, IG consumes the electrical power from the grid. This power is needed to build the flux in the windings of the IG. This power is also stored as kinetic energy in WG. When the speed goes beyond the synchronous speed, then only the WG starts supplying the electrical power.

- Voltage of the network drops significantly during the starting period of WG. The problem of voltage drop can be mitigated by starting the individual WGs sequentially.

- When IG starts generating the power then FC generation also oscillates. That means each generator has some effect to other generators.

- Total demand decreases after occurrence of fault at the bus where grid is connected. But total demand increases when fault occurs at any other buses which are remote from the grid. This is because during fault period real power loss in the network increases to very high value due to large resistance of distribution network and this extra power is supplied by the grid. When fault occurs at the bus where grid is connected, grid power can not come to the network side therefore total power requirement decreases.

\section{References}

[1] L. Ntziachristos, C. Kouridis, Z. Samaras, and K. Pattas, "A wind-power fuel-cell hybrid system study on the noninterconnected Aegean islands grid", Renewable energy, 2005, 30, (10), pp. 1471-1487

[2] J. Morren, and S. W. H.de Haan, and J. A. Ferreira, "Primary power/frequency control with wind turbines and fuel cells", in Proc. IEEE PES GM, 2006, pp. 1-8

[3] B. Delfino, and F. Fornari, "Modeling and control of an integrated fuel cell-wind turbine system", in Proc. Powertech Conference, Bologna, Italy, June 2003

[4] R. Chedid, F. B. Chaaban, R. Shihab, "A simplified electric circuit model for the analysis of hybrid wind-fuel cell systems", in Proc. IEEE PES GM, 2007, pp. 1-6

[5] M. T. Iqbal, "Modeling and control of wind fuel cell hybrid energy system", Renewable energy, 2003, 28, (2), pp. 223-237

[6] S. Leva, D. Zaninelli, "Hybrid renewable energy-fuel cell system: design and performance evaluation", Electric power systems research, 2009, Vol. 79, Issue 2, pp. 316324

[7] J. Padulles, G. W. Ault, and J. R. McDonald, "An integrated SOFC plant dynamic model for power systems simulation", Journal of power sources, 2000, Vol. 86, Issue 1-2, pp. 495-500

[8] R. Datta, and V. T. Ranganathan, "Variable-speed wind power generation using doubly fed wound rotor induction machine-a comparison with alternative schemes", IEEE Transactions on energy conversion, 2002, Vol. 17, Issue 3, pp. 414- 421

[9] R. Wamkeue, S. Moraogue, and I. Kamwa, "Distribution network fed in co-generation by induction generators: incidence of self excitation phenomenon", in Proc. IEMDC 2001, pp. 594-603

[10] A. A. El-Sattar, N. H. Saad, and M. Z. S. El-Dein, "Dynamic response of doubly fed induction generator variable speed wind turbine under fault", Electric power systems research, 2008, Vol. 78, Issue 7, pp. 1240-1246

[11] J. G. Slootweg, S. W. H. Haan, H. Polinder, and W. L. Kling, "General model for representing variable speed wind turbines in power system dynamics simulations", IEEE Transactions on power systems, 2003, Vol. 18, Issue 1, pp. 144-151

[12] J. B. Ekanayake, L. Holdsworth, and N. Jenkins, "Comparison of $5^{\text {th }}$ order and $3^{\text {rd }}$ order machine models for doubly fed induction generator (DFIG) wind turbines", Electric Power Systems Research, Vol. 67, Issue 3, 2003, pp. 207-215

[13] M. H. Nehrir, and C. Wang, "Dynamic modeling and simulation of solid oxide fuel cells", in "Modeling and control of fuel cells', IEEE press, 2009, pp. 85-86

[14] Fuel cell handbook, VII Ed., EG \& G Technical Services, Inc., Available: http://www.netl.doe.gov/technologies/coalpower/fuelcells /seca/pubs/FCHandbook7.pdf, 2004

[15] N. Jenkins, R. Allan, P. Crossely, D. Kirschen, and G. Strbac, "System studies in Embedded generation", IEE press, 2000, pp. 49-95 